\title{
How small is enough for the left heart decompression cannula during extracorporeal membrane oxygenation?
}

\author{
Sua Kim¹,2, Jin Seok Kim², Jae Seung Shin ${ }^{3}$, Hong Ju Shin ${ }^{3}$ \\ ${ }^{1}$ Department of Critical Care Medicine, ${ }^{2}$ Division of Cardiology, Department of Internal Medicine, and ${ }^{3}$ Department of Thoracic and Cardiovascular Surgery, \\ Korea University Ansan Hospital, Korea University College of Medicine, Ansan, Korea
}

Background: Left ventricular (LV) distension is a recognizable problem accompanied by subsequent complications during venoarterial extracorporeal membrane oxygenation (VA-ECMO). However, no gold standard for LV decompression has been established, and no minimal flow requirement has been designated. Thus, we evaluated the efficacy of the 8-Fr Mullins sheath for left heart decompression during VA-ECMO in adult patients.

Methods: Left heart decompression was performed when severe pulmonary edema was detected on chest radiography or when no generation of pulse pressure followed severe LV dysfunction in patients receiving VA-ECMO. We punctured the interatrial septum and inserted an 8-Fr Mullins sheath into the left atrium via the femoral vein. The sheath was connected to the venous catheter used for ECMO. The catheter was maintained during VA-ECMO.

Results: The left heart decompression procedure was performed in seven of 35 patients who received VA-ECMO between February 2017 and June 2018. Three patients had acute myocardial infarction; three, fulminant myocarditis; and one, dilated cardiomyopathy. Four patients showed noticeable improvement of pulmonary edema within 3 days, and three patients with a pulse pressure of $<10 \mathrm{~mm} \mathrm{Hg}$ showed an increase in pulse pressure of $>20 \mathrm{~mm} \mathrm{Hg}$ within 24 hours from the left heart decompression procedure. All seven patients were successfully weaned from VA-ECMO. No complications related to the left heart decompression procedure occurred.

Conclusions: An 8-Fr sheath may be a possible option for left heart decompression in adult patients with LV distension under VA-ECMO who are expecting recovery of LV function.

Key Words: extracorporeal membrane oxygenation; left heart decompression; left ventricular distension

\section{INTRODUCTION}

Left ventricular (LV) distension is a common complication during venoarterial extracorporeal membrane oxygenation (VA-ECMO) [1], and LV distension may cause subsequent problems [2-4]. Therefore, several strategies have been devised to improve LV distension. An intraaortic balloon pump, transaortic ventilation via the pigtail catheter, a catheter-based transaortic axial flow pump, left atrial (LA) decompression by venting catheter insertion, and interatrial septostomy are possible solutions [2]. These procedures have been found to be effi-

\section{Original Article}

Received: May 30, 2019

Revised: September 18, 2019

Accepted: November 4, 2019

Corresponding author

Hong Ju Shin

Department of Thoracic and

Cardiovascular Surgery, Korea

University Ansan Hospital, Korea

University College of Medicine, 123

Jeokgeum-ro, Danwon-gu, Ansan

15355, Korea

Tel: +82-31-412-5060

Fax: +82-31-414-3249

E-mail: babymedi@naver.com

Co-Corresponding author Jae Seung Shin

Department of Thoracic and

Cardiovascular Surgery, Korea

University Ansan Hospital, Korea

University College of Medicine, 123

Jeokgeum-ro, Danwon-gu, Ansan

15355, Korea

Tel: +82-31-412-5680

Fax: +82-31-414-3249

E-mail: jason@korea.ac.kr

Copyright @ 2019 The Korean Society of Critical Care Medicine

This is an Open Access article distributed under the terms of Creative Attributions Non-Commercial License (http://

creativecommons.org/li-censes/by-nc/4.0/) which permits unrestricted noncommercial use, distribution, and reproduction in any medium, provided the original work is properly cited. 
cacious $[5,6]$. However, there is no consensus on the appropriate method for LV decompression, and the flow rate required for proper decompression is unknown.

LA venting catheter insertion is a commonly performed procedure for $\mathrm{LV}$ decompression in patients receiving VA-ECMO. However, the LA venting procedure may cause procedure-related complications, especially when a large catheter is inserted, whereas a small catheter may lead to problems of inadequate LV decompression. Therefore, the size of the catheter for the procedure should be selected carefully.

We hypothesized that LA drainage with an 8-Fr catheter, which is smaller than the catheter usually inserted for LV decompression in adult patients, may effectively decompress the left heart for adult patients receiving VA-ECMO who show signs of LV distension. For patients who showed signs of LV distension, we performed left heart decompression by inserting an 8-Fr Mullins sheath in the LA and evaluated the final outcomes and efficacy of the procedure, focusing on the improvement of pulmonary edema and development of pulse pressure.

\section{MATERIALS AND METHODS}

\section{Study Population}

From February 2017 to June 2018, 35 adult patients received VA-ECMO in Korea University Ansan Hospital. When pulmonary edema was aggravated or pulse pressure deteriorated in patients receiving VA-ECMO, we considered left heart decompression. The Institutional Review Board of Korea University Ansan Hospital approved the study protocol and waived the requirement for informed consent (IRB No. 2018AS0190).

\section{ECMO Implantation and Management}

The indication for and characteristics of ECMO were decided by cardiovascular surgeons, cardiologists, and/or emergency department physicians when they encountered patients with refractory cardiogenic shock or patients under cardiopulmonary resuscitation. The catheter for ECMO was inserted percutaneously with the peripheral vascular approach by cardiovascular surgeons using the Seldinger technique. Cannulation was most commonly performed in the femoral vein and femoral artery. The size of the cannula ranged from 16 to $18 \mathrm{Fr}$ for the femoral artery and from 20 to $22 \mathrm{Fr}$ for the femoral vein. The Capiox Emergency Bypass System (Capiox EBS, Terumo Inc., Tokyo, Japan) and Permanent Life Support (Maquet, Rastatt, Germany) were used. Continuous unfractionated heparin was infused to maintain the activated partial thromboplas-

\section{KEY MESSAGES}

- We performed a left heart decompression with an 8-Fr Mullins sheath, which is a smaller catheter than that usually inserted for the left atrial venting procedure.

- All seven patients who underwent the procedure were successfully weaned from the extracorporeal membrane oxygenation (ECMO).

- Even an 8-Fr catheter may be used reliably for left heart decompression in adult patients receiving venoarterial ECMO and expecting left ventricular functional recovery.

tin time between 45 and 60 seconds, or activated clotting time between 140 and 180 seconds. We tried to maintain the mean arterial pressure between 65 and $80 \mathrm{~mm} \mathrm{Hg}$.

\section{Left Heart Decompression Procedure}

Patients who showed progression of significant pulmonary congestion on chest radiography with or without bilateral moist rales at chest auscultation, pink frothy expectoration, and low pulse pressure during VA-ECMO were considered for the left heart decompression procedure. The procedure was also considered when ECMO was indicated if the pulmonary congestion was very severe. For the left heart decompression procedure, we used an 8-Fr Mullins sheath. First, a Brockenbrough needle was inserted in the right atrium via an 8-Fr vascular sheath (Mullins sheath) from the femoral vein. Transseptal puncture was performed under fluoroscopic guidance. The Mullins sheath was then inserted in the left atrium over the Brockenbrough needle, and then the needle was removed. A three-way connector connected the Mullins sheath and venous catheter of the ECMO device for drainage.

\section{Data Collection and Outcomes}

Laboratory data and information on age, sex, and primary cardiac problems causing refractory cardiogenic shock were collected from the patients' medical records and reviewed. Changes in vital signs after ECMO support and after the left heart decompression procedure were closely monitored. The efficacy of the procedure was evaluated on the basis of the improvement of the pulmonary edema observed on chest radiography and the development of pulse pressure after the procedure.

\section{RESULTS}

The left heart decompression procedure was performed in 
seven patients during VA-ECMO. The median age of the patients was 58 years (range, 22 to 70 years) and body surface area was $1.78 \mathrm{~m}^{2}$ (range, 1.54 to $2.12 \mathrm{~m}^{2}$ ). Three patients had acute myocardial infarction, three patients had fulminant myocarditis, and one patient had dilated cardiomyopathy. Four patients had extracorporeal cardiopulmonary resuscitation. The left heart decompression procedure was performed immediately after the start of ECMO in four patients. In one patient, the procedure was performed within 24 hours from the start of ECMO. Among all seven patients, two patients were not supported by a mechanical ventilator. Before the left heart decompression, four patients showed severe pulmonary edema and four showed decreased pulse pressure of $<10 \mathrm{~mm} \mathrm{Hg}$ (Table 1). The median duration of VA-ECMO in all the patients was 185 hours (range, 82 to 342 hours). All the patients were successfully weaned from the ECMO, although one patient died of septic shock three weeks after ECMO weaning. One patient underwent heart transplantation (Table 2).

After the left heart decompression procedure, four patients showed improvement of pulmonary edema within 3 days (Figure 1). Among these four patients, two showed marked improvement of pulmonary edema within 24 hours. Among the other three patients, one took 6 days to attain improvement of pulmonary edema, and the other two developed pneumonia; therefore, we could not estimate the effect of left heart decompression by the improvement of pulmonary edema from the chest radiograph. Four patients, including two with very weak pulse pressure ( $<5 \mathrm{~mm} \mathrm{Hg}$ ) and one without improvement of pulmonary edema, showed a noticeable increase in pulse pressure within 24 hours from the left heart decompression procedure. One patient experienced aggravation of pulmonary congestion and decreased pulse pressure due to obstruction of the decompression catheter (Table 2).

Table 1. Baseline characteristics of the patients

\begin{tabular}{|c|c|c|c|c|c|c|c|c|c|c|}
\hline $\begin{array}{l}\text { Patient } \\
\text { No. }\end{array}$ & $\begin{array}{l}\text { Age } \\
(\mathrm{yr})\end{array}$ & Sex & $\mathrm{BSA}\left(\mathrm{m}^{2}\right)$ & $\mathrm{DM}$ & HTN & Other & $\begin{array}{l}\text { Cause of } \\
\text { shock }\end{array}$ & $\begin{array}{l}\text { Cardiac arrest } \\
\text { before ECMO start }\end{array}$ & ECPR & $\begin{array}{c}\text { MV } \\
\text { support }\end{array}$ \\
\hline 1 & 56 & Male & 1.81 & No & Yes & & $\mathrm{Ml}$ & Yes & Yes & Yes \\
\hline 2 & 56 & Female & 1.54 & No & No & $\begin{array}{l}\text { Previously on ECMO support } \\
\text { due to myocarditis }\end{array}$ & Myocarditis & No & No & No \\
\hline 3 & 70 & Male & 1.72 & Yes & No & RWMA due to old MI & $\mathrm{Ml}$ & Yes & Yes & Yes \\
\hline 4 & 58 & Male & 2.12 & No & No & & Myocarditis & Yes & Yes & Yes \\
\hline 5 & 22 & Female & 1.69 & No & No & & DCMP & Yes & No & Yes \\
\hline 6 & 59 & Male & 1.79 & No & No & & $\mathrm{Ml}$ & Yes & Yes & Yes \\
\hline 7 & 66 & Female & 1.78 & Yes & Yes & & Myocarditis & No & No & No \\
\hline
\end{tabular}

BSA: body surface area; DM: diabetes mellitus; HTN: hypertension; ECMO: extracorporeal membrane oxygenation; ECPR: extracorporeal cardiopulmonary resuscitation; MV: mechanical ventilation; MI: myocardial infarction; RWMA: regional wall motion abnormality; DCMP: dilated cardiomyopathy.

Table 2. Clinical outcomes of patients who underwent venoarterial ECMO and insertion of the left heart decompression catheter

\begin{tabular}{|c|c|c|c|c|c|c|c|}
\hline $\begin{array}{l}\text { Patient } \\
\text { No. }\end{array}$ & Outcome & $\begin{array}{l}\text { Survival } \\
\text { discharge }\end{array}$ & $\begin{array}{c}\text { ECMO } \\
\text { duration (hr) }\end{array}$ & $\begin{array}{l}\text { Time from ECMO insertion to } \\
\text { venting catheter insertion }\end{array}$ & $\begin{array}{l}\text { Improvement in } \\
\text { pulmonary edema }\end{array}$ & $\begin{array}{c}\text { Change in } \\
\text { pulse pressure }^{\mathrm{a}}\end{array}$ & Complication \\
\hline 1 & Successful weaning & Yes & 235 & Immediate & $\begin{array}{l}\text { Unable to confirm } \\
\text { due to pneumonia }\end{array}$ & $3 \rightarrow 34$ & \\
\hline 2 & Successful weaning & No & 342 & $30 \mathrm{hr}$ & 6 day & $4 \rightarrow 8$ & \\
\hline 3 & Successful weaning & Yes & 82 & Immediate & 1 day & $8 \rightarrow 26$ & \\
\hline 4 & Successful weaning & Yes & 131 & $15 \mathrm{hr}$ & $\begin{array}{l}\text { Unable to confirm } \\
\text { due to pneumonia }\end{array}$ & - & $\begin{array}{l}\text { Venting catheter } \\
\text { obstruction }\end{array}$ \\
\hline 5 & Bridge to transplantation & Yes & 198 & Immediate & $6 \mathrm{hr}$ & $7 \rightarrow 41$ & \\
\hline 6 & Successful weaning & Yes & 68 & Immediate & 3 day & $0 \rightarrow 42$ & \\
\hline 7 & Successful weaning & Yes & 185 & $40 \mathrm{hr}$ & 3 day & $16 \rightarrow 20$ & \\
\hline
\end{tabular}

ECMO: extracorporeal membrane oxygenation.

aLowest pulse pressure within 12 hours from venting catheter insertion $\rightarrow$ pulse pressure after 24 hours from venting catheter insertion ( $\mathrm{mm}$ Hg). 

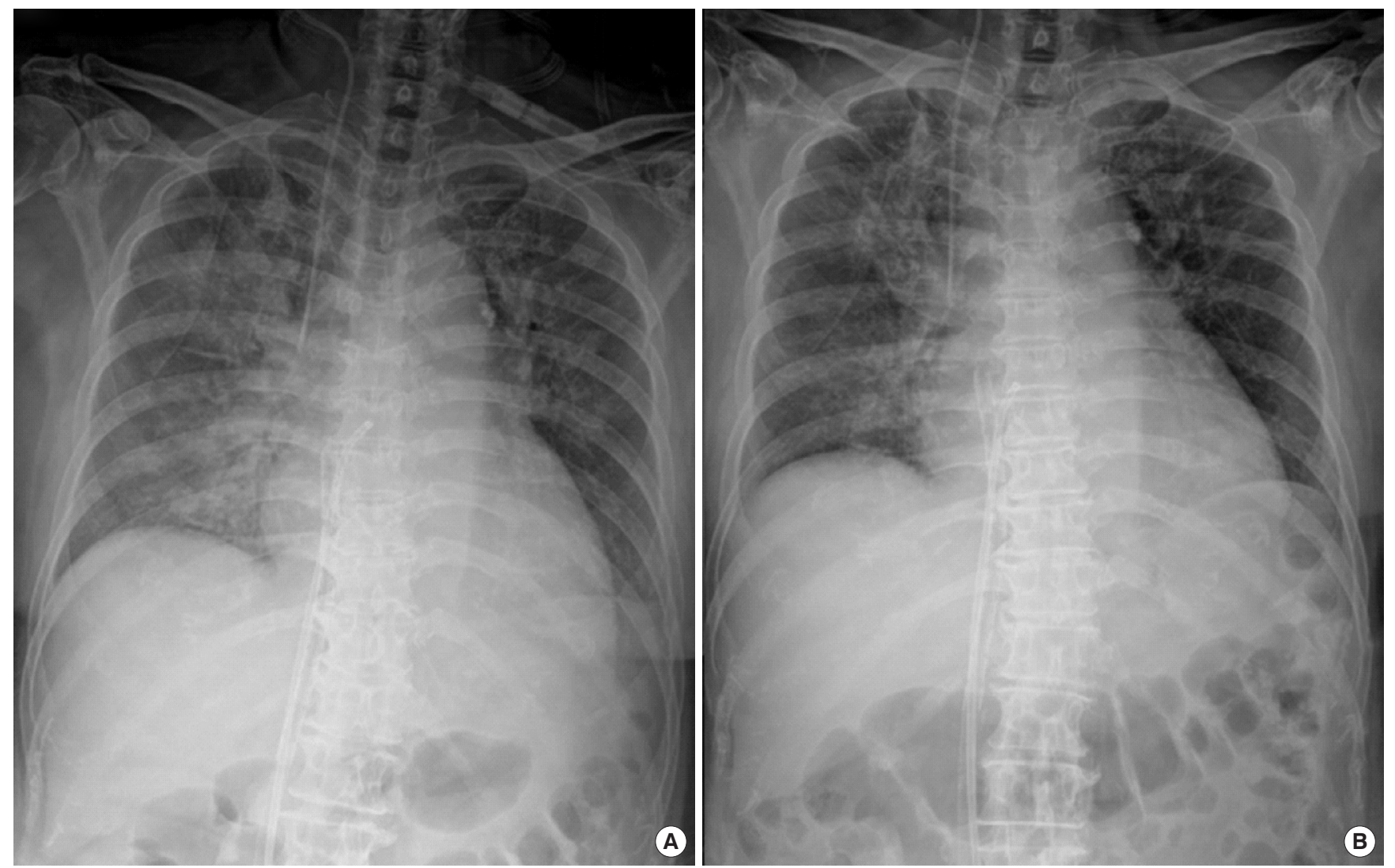

Figure 1. Improvement of pulmonary edema after left heart decompression catheter insertion. (A) Chest radiograph taken immediately after left heart decompression catheter insertion. (B) Chest radiograph taken 24 hours after venting catheter insertion.

\section{DISCUSSION}

For the seven patients who received VA-ECMO and had LV distension, we performed a left heart decompression procedure using an 8-Fr Mullins sheath. We checked the efficacy of the procedure in all seven patients, all of whom were successfully weaned from VA-ECMO, including one who underwent heart transplantation. Four patients showed improvement of pulmonary edema within three days from the procedure, and four patients showed a noticeable increase in pulse pressure within 24 hours.

$\mathrm{LV}$ distension is a common event during VA-ECMO. The incidence of LV distension ranges from $12 \%$ to $68 \%$ [7-9]. LV distension results in subsequent complications of pulmonary edema and LV thrombus [10]. The functional recovery of the $\mathrm{LV}$ also is disturbed by LV distension [2]. Therefore, the prognosis of patients who develop such complications is worse than that of patients without LV distension during ECMO [11].

Although no guidelines or gold standard has been established for the management of LV distension during VA-ECMO, several methods have been used to improve LV distension. An intra-aortic balloon pump was used to reduce the LV afterload and improve coronary artery flow [12]. Building a venting flow from the left heart is another method. To create a drain directly from the LV, a transaortic catheter or axial flow pump can be used [13-15]. LA venting is also effective in this condition because $\mathrm{LV}$ distension is accompanied by considerable mitral regurgitation, sometimes with the impairment of the mitral apparatus. Interatrial septostomy $[16,17]$ or insertion of a LA venting catheter through the interatrial septum and connecting the catheter to the venous catheter of ECMO $[18,19]$ is performed for LA venting. However, each procedure is associated with the risk of additional bleeding, and fluoroscopy or transesophageal echocardiography guidance is required to avoid opening the chest cavity. LA venting strategies with interatrial septostomy or insertion of a large catheter in the left atrium via the interatrial septum may lead to iatrogenic atrial septal defects.

For patients receiving VA-ECMO who have LV distension, we tried to decompress the left heart with an 8-Fr Mullins sheath. The 8-Fr catheter is much smaller in size than the catheters generally inserted for LA venting in adult patients receiving 
VA-ECMO $[18,20]$. The use of smaller catheters resulted in fewer complications, with no procedure-related bleeding in our patients. The cost of the procedure was less than the other procedures, and handling of the catheter was also easy during and after the procedure in our patients. The only complication in our study was catheter obstruction due to thrombus in patient 4 , who showed delayed improvement of pulmonary edema. We thought that the thrombus developed as a result of the low activated coagulation time, which was $<120$ seconds on that day. However, the efficacy of our procedure was proven by this case. The pulmonary edema of patient 4 was aggravated after the obstruction of the catheter.

When inserting the decompression catheter, the catheter should have a sufficient flow rate because if the flow rate is very low, the LV distension cannot be relieved properly. Although we did not measure the flow rate of the decompression catheter, we expected the flow rate to be approximately $300 \mathrm{ml} / \mathrm{min}$, based on our experience [21]. Another article also reported that the flow rate of the 8-Fr LA venting catheter in humans was up to $270 \mathrm{ml} / \mathrm{min}$ [18]. A flow rate of approximately 300 $\mathrm{ml} / \mathrm{min}$ might be enough for adult patients receiving VA-EC$\mathrm{MO}$, since the flow rate to the left atrium from the bronchial artery, which is maintained when cardiac function is stopped, is $1 \%$ of the cardiac output [22]. However, the required flow rate for left heart decompression varies according to the condition of patients (e.g., remaining cardiac function and duration of VA-ECMO). We think that a flow rate of approximately $300 \mathrm{ml} / \mathrm{min}$ for left heart decompression may meet the flow requirement for left heart decompression in patients who are expecting LV functional recovery soon. Finally, our patients recovered from the LV distension and were weaned from ECMO successfully. We suggest that an 8-Fr catheter may be another option for left heart decompression when recovery of LV systolic function is expected.

\section{Limitations}

As we did not use the Swan-Ganz catheter, we did not obtain precise hemodynamic data and evidence for increased LV end diastolic pressure in our patients. Moreover, we did not measure the changes in LV dimensions, stroke volume, or systolic function before and after the procedure. We evaluated only the clinical symptoms and signs of the patients rather than the objective parameters before and after the left heart decompression procedure. Likewise, we did not measure the precise flow rate of the LA venting catheter. Instead, the efficacy of the procedure was indirectly reflected by the increase in pulse pressure and the improvement of pulmonary edema. The col- or of the blood in the LA venting catheter also indicated improvement of pulmonary edema after the procedure. Finally, long-term follow-up data were not obtained; hence, the development of complications such as iatrogenic atrial septal defects and related complications in patients who survived from the cardiac event was not evaluated. However, we expect that only a small part or trace of the defect would remain.

In this study, we report the efficacy of left heart decompression with an 8-Fr Mullins sheath in patients receiving VA-EC$\mathrm{MO}$ and presenting $\mathrm{LV}$ distension. Most of the patients showed significant improvement of pulmonary edema, and all were successfully weaned from ECMO support. This implies that even a small amount of LA drainage with close monitoring of the patency and efficacy of the catheter may be effective for relieving distended LV, improving the patient outcome. Left heart decompression with a small catheter may be a possible choice without mechanical complications, especially for patients expecting recovery of $\mathrm{LV}$ function.

\section{CONFLICT OF INTEREST}

No potential conflict of interest relevant to this article was reported.

\section{ORCID}

Sua Kim

Jin Seok Kim

https://orcid.org/0000-0003-3513-7261

Jae Seung Shin https://orcid.org/0000-0001-5951-8013

Hong Ju Shin https://orcid.org/0000-0001-8147-6665 https://orcid.org/0000-0002-0731-3523

\section{AUTHOR CONTRIBUTIONS}

Conceptualization: HJS, JSS. Data curation: HJS. Formal analysis: SK. Methodology: JSK. Project administration: JSS. Visualization \& Writing - original draft: SK. Writing - review \& editing: HJS.

\section{REFERENCES}

1. Cheng R, Hachamovitch R, Kittleson M, Patel J, Arabia F, Moriguchi J, et al. Complications of extracorporeal membrane oxygenation for treatment of cardiogenic shock and cardiac arrest: a meta-analysis of 1,866 adult patients. Ann Thorac Surg 2014;97:610-6.

2. Soleimani B, Pae WE. Management of left ventricular distension during peripheral extracorporeal membrane oxygenation 
for cardiogenic shock. Perfusion 2012;27:326-31.

3. Ostadal P, Mlcek M, Kruger A, Hala P, Lacko S, Mates M, et al. Increasing venoarterial extracorporeal membrane oxygenation flow negatively affects left ventricular performance in a porcine model of cardiogenic shock. J Transl Med 2015;13:266.

4. Makdisi G, Hashmi ZA, Wozniak TC, Wang IW. Left ventricular thrombus associated with arteriovenous extra corporeal membrane oxygenation. J Thorac Dis 2015;7:E552-4.

5. Alhussein M, Osten M, Horlick E, Ross H, Fan E, Rao V, et al. Percutaneous left atrial decompression in adults with refractory cardiogenic shock supported with veno-arterial extracorporeal membrane oxygenation. J Card Surg 2017;32:396-401.

6. Fiedler AG, Dalia A, Axtell AL, Ortoleva J, Thomas SM, Roy N, et al. Impella placement guided by echocardiography can be used as a strategy to unload the left ventricle during peripheral venoarterial extracorporeal membrane oxygenation. J Cardiothorac Vasc Anesth 2018;32:2585-91.

7. Hanna BD. Left atrial decompression: is there a standard during extracorporeal support of the failing heart? Crit Care Med 2006;34:2688-9.

8. Frazier EA, Faulkner SC, Seib PM, Harrell JE, Van Devanter $\mathrm{SH}$, Fasules JW. Prolonged extracorporeal life support for bridging to transplant: technical and mechanical considerations. Perfusion 1997;12:93-8.

9. Fiser WP, Yetman AT, Gunselman RJ, Fasules JW, Baker LL, Chipman CW, et al. Pediatric arteriovenous extracorporeal membrane oxygenation (ECMO) as a bridge to cardiac transplantation. J Heart Lung Transplant 2003;22:770-7.

10. Weber C, Deppe AC, Sabashnikov A, Slottosch I, Kuhn E, Eghbalzadeh $\mathrm{K}$, et al. Left ventricular thrombus formation in patients undergoing femoral veno-arterial extracorporeal membrane oxygenation. Perfusion 2018;33:283-8.

11. Truby LK, Takeda K, Mauro C, Yuzefpolskaya M, Garan AR, Kirtane AJ, et al. Incidence and implications of left ventricular distention during venoarterial extracorporeal membrane oxygenation support. ASAIO J 2017;63:257-65.

12. Ma P, Zhang Z, Song T, Yang Y, Meng G, Zhao J, et al. Combining ECMO with IABP for the treatment of critically Ill adult heart failure patients. Heart Lung Circ 2014;23:363-8.

13. Cheng A, Swartz MF, Massey HT. Impella to unload the left ventricle during peripheral extracorporeal membrane oxy- genation. ASAIO J 2013;59:533-6.

14. Fumagalli R, Bombino M, Borelli M, Rossi F, Colombo V, Osculati G, et al. Percutaneous bridge to heart transplantation by venoarterial ECMO and transaortic left ventricular venting. Int J Artif Organs 2004;27:410-3.

15. Hong TH, Byun JH, Yoo BH, Hwang SW, Kim HY, Park JH. Successful left-heart decompression during extracorporeal membrane oxygenation in an adult patient by percutaneous transaortic catheter venting. Korean J Thorac Cardiovasc Surg 2015; 48:210-3.

16. Baruteau AE, Barnetche T, Morin L, Jalal Z, Boscamp NS, Le Bret E, et al. Percutaneous balloon atrial septostomy on top of venoarterial extracorporeal membrane oxygenation results in safe and effective left heart decompression. Eur Heart J Acute Cardiovasc Care 2018;7:70-9.

17. Lin YN, Chen YH, Wang HJ, Hung JS, Chang KC, Lo PH. Atrial septostomy for left atrial decompression during extracorporeal membrane oxygenation by inoue balloon catheter. Circ J 2017;81:1419-23.

18. Aiyagari RM, Rocchini AP, Remenapp RT, Graziano JN. Decompression of the left atrium during extracorporeal membrane oxygenation using a transseptal cannula incorporated into the circuit. Crit Care Med 2006;34:2603-6.

19. Kotani Y, Chetan D, Rodrigues W, Sivarajan VB, Gruenwald C, Guerguerian AM, et al. Left atrial decompression during venoarterial extracorporeal membrane oxygenation for left ventricular failure in children: current strategy and clinical outcomes. Artif Organs 2013;37:29-36.

20. Lee SI, Lee SY, Choi CH, Park KY, Park CH. Left heart decompression in acute complicated myocardial infarction during extracorporeal membrane oxygenation. J Intensive Care Med 2017;32:405-8.

21. Kim HE, Jung JW, Shin YR, Park HK, Park YH, Shin HJ. Left atrial decompression by percutaneous left atrial venting cannula insertion during venoarterial extracorporeal membrane oxygenation support. Korean J Thorac Cardiovasc Surg 2016; 49:203-6.

22. Fritts HW Jr, Harris P, Chidsey CA 3rd, Clauss RH, Cournand A. Estimation of flow through bronchial-pulmonary vascular anastomoses with use of T-1824 dye. Circulation 1961;23:390-8. 